OPEN ACCESS

Edited by:

Gaogian Feng,

Burnet Institute, Australia

Reviewed by:

Charlene Wilma Joyce Africa, University of the Western Cape,

South Africa

Pedro Vieira Baptista,

Hospital Lusíadas Porto, Portugal

${ }^{*}$ Correspondence:

Cha Han

tjhancha@163.com

Fengxia Xue

fengxiaxue1962@gmail.com

Specialty section:

This article was submitted to

Clinical Microbiology,

a section of the journal

Frontiers in Cellular and

Infection Microbiology

Received: 17 August 2021 Accepted: 19 October 2021

Published: 02 November 2021

Citation:

Qi W, Li H, Wang C, Li H, Zhang B, Dong M, Fan A, Han C and Xue F

(2021) Recent Advances in

Presentation, Diagnosis and

Treatment for Mixed Vaginitis.

Front. Cell. Infect. Microbiol. 11:759795.

doi: 10.3389/fcimb.2021.759795

\section{Recent Advances in Presentation, Diagnosis and Treatment for Mixed Vaginitis}

\author{
Wenhui $\mathrm{Qi}^{1,2}$, Huanrong $\mathrm{Li}^{1,2}$, Chen Wang ${ }^{1,2}$, Huiyang $\mathrm{Li}^{1,2}$, Bingbing Zhang ${ }^{1,2}$, \\ Mengting Dong ${ }^{1,2}$, Aiping Fan ${ }^{1,2}$, Cha Han ${ }^{1,2 *}$ and Fengxia Xue ${ }^{1,2 *}$ \\ 1 Department of Gynecology and Obstetrics, Tianjin Medical University General Hospital, Tianjin, China, ${ }^{2}$ Tianjin Key \\ Laboratory of Female Reproductive Health and Eugenic, Department of Gynecology and Obstetrics, Tianjin Medical \\ University General Hospital, Tianjin, China
}

Mixed vaginitis is the simultaneous presence of at least two types of vaginitis, contributing to an abnormal vaginal milieu and leading to vaginal symptoms and signs. However, associations between symptoms and the type of mixed vaginitis have not been clearly elucidated, and research on mixed vaginitis is still in the preliminary stage. Therefore, the pathogenic mechanism of mixed vaginitis remains understudied. Mixed vaginitis generally involves the formation of mixed biofilms. The study of polymicrobial interactions and mixed biofilms will provide a new idea for the understanding of mixed vaginitis. Moreover, this review summarizes some effective management and laboratory diagnosis of mixed vaginitis to avoid inappropriate therapy, recurrence, and reinfection. It is of high clinical importance to obtain relevant clinical data to improve clinical knowledge about mixed vaginitis.

\section{Keywords: aerobic vaginitis, desquamative inflammatory vaginitis, cytolytic vaginosis, mixed vaginitis, vulvovaginal} candidiasis, bacterial vaginosis, trichomoniasis, mixed biofilms

\section{INTRODUCTION}

Mixed vaginitis is the simultaneous presence of at least two types of vaginitis, contributing to an abnormal vaginal milieu and leading to vaginal symptoms and signs. Nevertheless, individual signs and symptoms have only limited value in the recognition of vaginitis in clinical practice. For example, in patients with simple vaginitis, "vulvar pruritis" and "thick curdy discharge" are more likely to be reported by women with vulvovaginal candidiasis (VVC), while "thin white discharge" and "odor" are more commonly reported by women with bacterial vaginitis (BV) (Rivers et al., 2011). However, "abnormal vaginal discharge," "dyspareunia," and "vaginal soreness" can occur with any kind of vaginitis. The presentation of mixed vaginitis can be atypical. Consequently, simply identifying the presence of at least two types of vaginitis does not establish a cause-effect relationship with clinical symptoms and signs. The concept of mixed vaginitis has escaped clinical scrutiny and definition.

Today, approximately 20 lower genital tract-related infections have been recognized, and such infections are caused by bacteria, fungi, protozoa, mycoplasma, and viruses (Mardha KT et al., 1998). The majority of infections in the female reproductive tract (FRT) occur in the vagina and cervix. Numerous microorganisms are often linked to cervical infection, leading to cervicitis, including herpes 
simplex virus-2 (HSV-2), Chlamydia trachomatis (CT), Neisseria gonorrheae (NG), and Mycoplasma (Laniewski et al., 2020). The most common forms of vaginitis include desquamative inflammatory vaginitis (DIV) or aerobic vaginitis (AV), bacterial vaginosis (BV), vulvovaginal candidiasis (VVC), cytolytic vaginosis $(\mathrm{CV})$ and trichomonas vaginalis (TV). Mixed vaginitis in this review encompasses these common types of vaginitis. The signs and symptoms of mixed vaginitis are often atypical, treatment is complicated in contrast to single-type vaginitis. It is largely ignored and poorly studied. Therefore, the major goal of this review is to help improve clinicians' understanding of mixed vaginitis and discuss the therapeutic standard to reduce the disease burden and prevent associated complications.

\section{METHOD}

Search Methods. A systematic search was performed in the PubMed database; search results were not limited by publication year. Search strings included the following: "mixed vaginitis", "mixed vaginal infection", "mixed biofilms", "polymicrobial infections", "vulvovaginal candidiasis", "bacterial vaginosis", "trichomoniasis", "aerobic vaginitis", "desquamative inflammatory vaginitis" and "cytolytic vaginosis". Additional potentially relevant studies that were not identified by the database search were identified by examining the references of the selected clinical studies and review articles. A total of 75 studies on mixed vaginitis were identified in our literature search.

Selection Criteria. The following inclusion criteria were used for study selection: studies on any type of vaginitis with information about clinical features, diagnosis and treatment; studies that reported the incidence of mixed vaginitis but we only choose the epidemiologic data of mixed vaginitis in the last 10 years; and studies on polymicrobial interactions. The exclusion criteria were as follows: studies not in English, letters, case reports or conference abstracts; only have the epidemiologic data of singe vaginitis were excluded in the epidemiologic data.

\section{EPIDEMIOLOGY}

Although vaginitis is common, affecting millions of women every year, little information about the prevalence of mixed vaginitis is available. A literature review to assess the occurrence and frequency of mixed vaginitis revealed that the proportion of mixed vaginitis ranged from $4.44 \%$ to $35.06 \%$ (Rivers et al., 2011; Wang et al., 2017). The representative data are depicted in Table 1. The following factors are limitations that prevent the obtention of a clear picture of the actual prevalence of mixed vaginitis.

The types of vaginitis observed have not been concordant. Evaluations have traditionally focused on VVC, BV, and TV. Most studies have reported that VVC plus BV is the most prevalent form of vaginitis (Rivers et al., 2011). In addition, it is possible that some clinicians are unaware of DIV/AV, thus sometimes misdiagnosing it as BV, affecting the epidemiological data. When DIV/AV is included, epidemiologic estimates shift considerably. Some studies indicated that DIV/AV plus BV, VVC plus DIV/AV, and VVC plus BV were the most frequent forms of mixed vaginitis (Fan et al., 2013).

There is great variability in the rates of mixed vaginitis in different populations. One study found a relatively low rate of mixed vaginitis (4.44\%) in Brazil (Rivers et al., 2011), while another found a higher rate $(35.06 \%)$ in Shanghai (Wang et al., 2017). Research is required to demonstrate prevalence and outcomes in various populations, such as pregnant women, hypoestrogenic women, asymptomatic women, and so on.

The diagnostic criteria and tools to determine the prevalence of mixed vaginitis differ. The classical standards for vaginitis diagnosis are physical examination, microscopy, and culture methods, which are usually performed in hospitals. The skill level of technicians is an influencing factor (Nyirjesy et al., 2020). Recent research has shown that some new molecular assays (Affirm VPIII, Aptima, BD Max, Seegene Allplex) for the diagnosis of mixed vaginitis have performed well, identifying proportions ranging from $7.58 \%$ to 27.23\% (Schwebke et al., 2020; Vieira-Baptista et al., 2021).

The vaginal and cervical microbiome is an intricate ecosystem containing various microbes in different ratios. At present, in the mixed vaginitis-related literature, only 5 common types of vaginitis are included. If one includes the cervical, but not strictly vaginal, pathogens such as HSV-2 virus, CT, NG, mycoplasma, and HPV may be included, and higher frequencies of mixed infections may be reported (Brotman et al., 2010).

There is a lack of physician understanding and implementation of current guidelines (Nyirjesy et al., 2020). This is likely due, in part, to the fact that the majority of these infections are diagnosed empirically without objective data. Moreover, mixed vaginitis symptoms can be nonspecific and vary by patient. Empirical evidence in this population has likely led to many misdiagnoses.

\section{MECHANISM OF MIXED VAGINITIS}

Multiple microorganisms generally involve the formation of mixed biofilms, dominated by bacteria and/or fungi, embedded in an extracellular matrix (Beaussart et al., 2013). The specific characteristics of mixed biofilms, especially their enhanced drug resistance and their ability to evade components of the host immune response, make them of high clinical importance. However, despite the importance of such mixed biofilms, mixed biofilms research, particularly research involving vastly interspecies interactions, is in its infancy (Schlecht et al., 2015). Bacteria and/or fungi can coexist within a host, and the nature of interspecies interactions can determine the fate of microbial populations. They influence each other in diverse ways via synergistic or antagonistic interactions (Lohse et al., 2018).

Medically antagonistic interactions between microorganism are common in the lower female reproductive tract. It is more likely to occur between probiotics and pathogens. For example, studies on the vaginal microbiota have revealed that Lactobacillus species lower the local $\mathrm{pH}$ (by releasing lactic acid), which results in the inhibition of initial adherence of Candida albicans and Gardnerella vaginalis to the vaginal mucosal surface (Deidda et al., 2016). Many environmental cues impact biofilm formation, such as hypoxia, 
TABLE 1 | Summary of representative data of mixed vaginitis in the last 10 years.

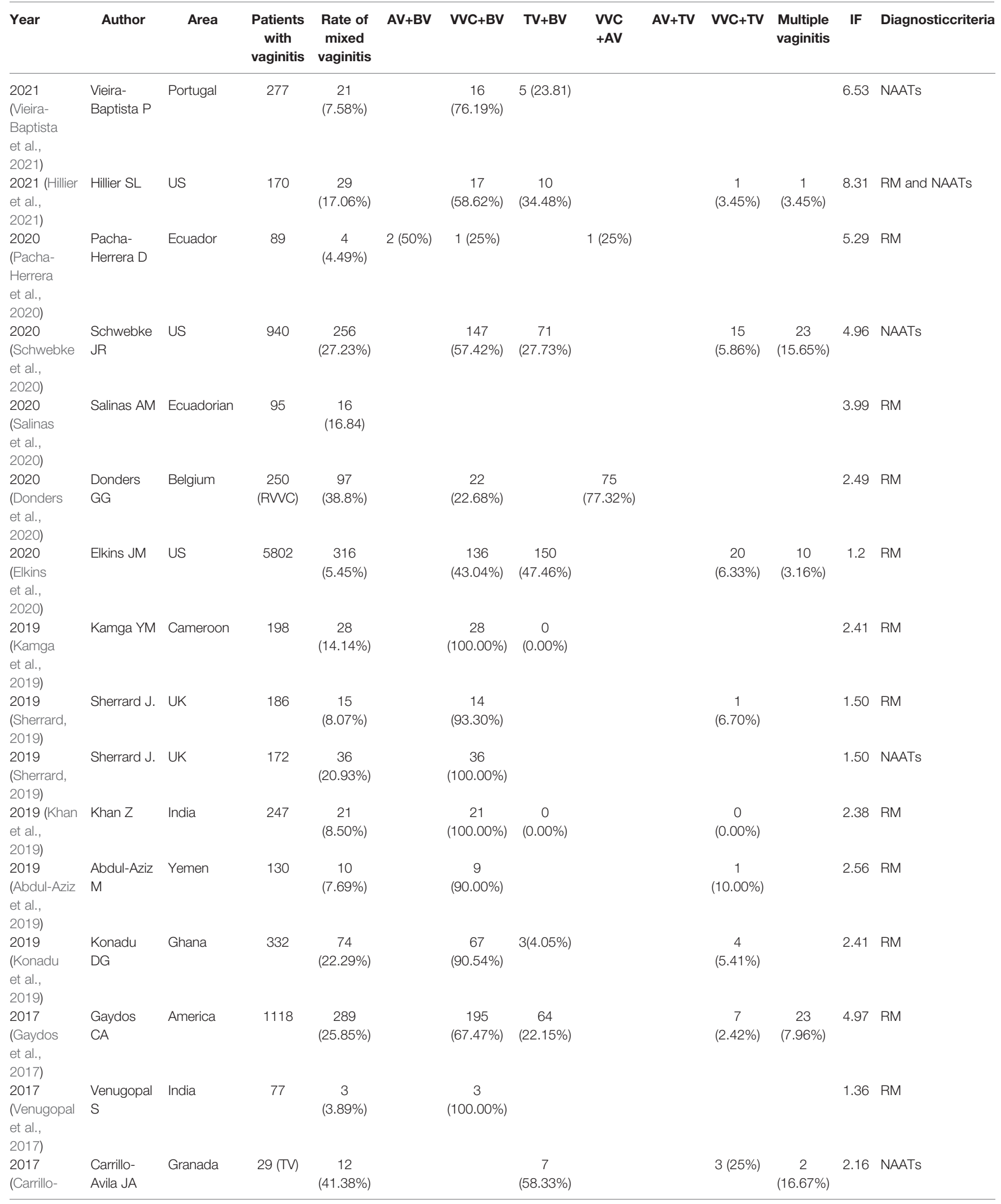


TABLE 1 | Continued

\begin{tabular}{|c|c|c|c|c|c|c|c|c|c|c|c|c|c|}
\hline Year & Author & Area & $\begin{array}{l}\text { Patients } \\
\text { with } \\
\text { vaginitis }\end{array}$ & $\begin{array}{c}\text { Rate of } \\
\text { mixed } \\
\text { vaginitis }\end{array}$ & $A V+B V$ & VVC+BV & TV+BV & $\begin{array}{l}\text { VVC } \\
+A V\end{array}$ & $A V+T V$ & VVC+TV & $\begin{array}{l}\text { Multiple } \\
\text { vaginitis }\end{array}$ & IF & Diagnosticcriteria \\
\hline \multicolumn{14}{|l|}{$\begin{array}{l}\text { Avila et al., } \\
\text { 2017) }\end{array}$} \\
\hline $\begin{array}{l}2017 \\
\text { (Wang } \\
\text { et al., } \\
2017)\end{array}$ & Wand HX & Shanghai & 4036 & $\begin{array}{c}1415 \\
(35.06 \%)\end{array}$ & & $\begin{array}{c}606 \\
(42.83 \%)\end{array}$ & $\begin{array}{c}471 \\
(33.27 \%)\end{array}$ & & & & & 1.50 & $\mathrm{RM}$ \\
\hline $\begin{array}{l}2016 \text { (Liang } \\
\text { et al., } \\
2016)\end{array}$ & Liang Q & Tianjin & $142(\mathrm{AV})$ & $\begin{array}{c}84 \\
(59.15 \%)\end{array}$ & $\begin{array}{c}36 \\
(42.85 \%)\end{array}$ & & & $\begin{array}{c}26 \\
(30.95 \%)\end{array}$ & $\begin{array}{c}22 \\
(26.19 \%)\end{array}$ & & & 1.39 & $\mathrm{RM}$ \\
\hline $\begin{array}{l}2016 \text { (Byun } \\
\text { et al., } \\
2016 \text { ) }\end{array}$ & Byun SW & Korea & 108 & $\begin{array}{c}10 \\
(9.26 \%)\end{array}$ & & & & & & & & 1.12 & NAATs \\
\hline $\begin{array}{l}2016 \\
\text { (Wang } \\
\text { et al., } \\
2016)\end{array}$ & Wang ZL & Chongqing & 830 & $\begin{array}{c}184 \\
(22.17 \%)\end{array}$ & $\begin{array}{c}101 \\
(54.90 \%)\end{array}$ & & & $\begin{array}{c}48 \\
(26.10 \%)\end{array}$ & $\begin{array}{c}15 \\
(8.20 \%)\end{array}$ & & $\begin{array}{c}20 \\
(10.80 \%)\end{array}$ & 1.20 & $\mathrm{RM}$ \\
\hline $\begin{array}{l}2013 \text { (Jahic } \\
\text { et al., } \\
2013 \text { ) }\end{array}$ & Jahic M & Sapna & 96 & $\begin{array}{c}30 \\
(31.30 \%)\end{array}$ & $\begin{array}{c}8 \\
(26.70 \%)\end{array}$ & & & $\begin{array}{c}13 \\
(43.30 \%)\end{array}$ & $\begin{array}{c}9 \\
(30.00 \%)\end{array}$ & & & 0.00 & $\mathrm{RM}$ \\
\hline $\begin{array}{l}2013 \text { (Fan } \\
\text { et al., } \\
2013 \text { ) }\end{array}$ & Fan A & Tianjin & 657 & $\begin{array}{c}170 \\
(25.88 \%)\end{array}$ & $\begin{array}{c}31 \\
(18.24 \%)\end{array}$ & $\begin{array}{c}62 \\
(36.47 \%)\end{array}$ & $\begin{array}{c}18 \\
(10.59 \%)\end{array}$ & $\begin{array}{c}32 \\
(18.82 \%)\end{array}$ & $\begin{array}{c}21 \\
(12.35 \%)\end{array}$ & $\begin{array}{c}1 \\
(0.58 \%)\end{array}$ & $\begin{array}{c}5 \\
(2.94 \%)\end{array}$ & 2.28 & $\mathrm{RM}$ \\
\hline $\begin{array}{l}2012 \\
\text { (Bohbot } \\
\text { et al., } \\
\text { 2012) }\end{array}$ & Bohbot JM & France & 118 & $\begin{array}{c}38 \\
(32.20 \%)\end{array}$ & & & & & & & & 0.00 & Unspecified \\
\hline $\begin{array}{l}2011 \\
\text { (Rivers } \\
\text { et al., } \\
2011 \text { ) }\end{array}$ & Rivers CA & Birmingham & 338 & $\begin{array}{c}15 \\
(4.44 \%)\end{array}$ & & $\begin{array}{c}15 \\
(100.00 \%)\end{array}$ & & & & & & 2.27 & $\mathrm{RM}$ \\
\hline $\begin{array}{l}2011 \\
\text { (Gondo } \\
\text { et al., } \\
\text { 2011) }\end{array}$ & Gondo F & Brazil & 112 & $\begin{array}{c}7 \\
(6.30 \%)\end{array}$ & & $\begin{array}{c}7 \\
(100.00 \%)\end{array}$ & & & & & & 1.30 & $\mathrm{RM}$ \\
\hline
\end{tabular}

elevated extracellular $\mathrm{pH}$, body temperature, and elevated $\mathrm{CO} 2$ (Castro et al., 2016). Similarly, a previous study reported that Lactobacillus in healthy women vaginally disrupted Gardnerella biofilm surface area, density and depth (Saunders et al., 2007). Little is known about pathophysiological vaginal conditions during mixed vaginitis, so the structure and composition of the mixed biofilm to understand mixed vaginitis needs to be further explored.

Some synergistic relationships result in complex pathogenic processes, providing protection to one or both species in mixedspecies biofilms. It is more likely to occur between pathogens. This occurs in the following ways: cells of certain species can directly bind to cells of other species. For example, recent evidence has indicated that Staphylococcus aureus can "piggyback" on C. albicans hyphae to penetrate host cells, infiltrate deep tissues and participate in the pathogenic process of host cells (Schlecht et al., 2015). Similar synergies providing a protective microenvironment have also been observed; for example, the presence of a C. albicans biofilm enables the proliferation of anaerobic pathogens in an otherwise hostile, oxygen-rich environment. Moreover, the bacteria seem to induce the formation of these protective structures (Fox et al., 2014). A recent study linked this protective interaction to enhanced drug resistance; when C. albicans and methicillin-resistant Staphylococcus aureus (MRSA) strains were grown together, the presence of C. albicans seemed to protect MRSA from eradication by vancomycin (Harriott and Noverr, 2010). Synergistic interactions can also enhance virulence during infection (Morales et al., 2013). For example, higher host mortality was observed when S. aureus and C. albicans were introduced together at sublethal doses in a mouse peritonitis infection model than when either species was introduced alone (Peters and Noverr, 2013). A limitation of these studies was that this interaction was evaluated not in the lower female reproductive tract. However, these observations illustrate the dynamic nature of polymicrobial interactions in part. In other words, the contemporaneous process may be interdependent. The mechanisms behind these synergistic interactions have not been described. 
We have focused on antagonistic versus synergistic interactions, but additional distinct interactions exist. Multiple microorganisms challenge the immune system in different ways compared with single microbe. A host response to one microbe may promote the proliferation of another microbe. For example, coinfection with Streptococcus agalactiae significantly attenuated the hyphal development of C. albicans in vitro, but it may attenuate host vaginal mucosal TH17 immunity and contribute to mucosal colonization by C. albicans in vivo (Yu et al., 2018). A multicountry cross-sectional study reported that the factor independently associated with $S$. agalactiae was $C$. albicans presence (Cools et al., 2016). Similarly, another study suggested that $C$. albicans may suppress the local host immune response, allowing subclinical $P$. aeruginosa to proliferate, resulting in disease (Roux et al., 2009) (Figure 1). Thus, these interactions are highly complex, and the type of interaction that occurs often depends on a range of environmental, pathogenic and host factors. The mechanisms of mixed vaginitis are unknown thus far, and further exploration is needed.

\section{CLINICAL FEATURES}

In single vaginitis, different types of vaginitis have different vaginal milieu and clinical manifestations. It is essential to compare the clinical manifestations and microorganisms in various vaginitis in order to recognize the mixed vaginitis. The representative content is depicted in Table 2. Mixed vaginitis may be atypical. It can be characterized by single vaginitis and can also be characterized by the simultaneous presence of two or more potential vaginitis features (Mardha KT et al., 1998; Fan et al., 2013). For example, patients with AV plus BV reported a genital fish-like odor more than a single AV and an inflammation more than a single BV. Patients with AV plus VVC more often reported genital itching than those with a single AV (Fan et al., 2013). Symptoms varied among the patients with mixed vaginitis. The most frequently reported symptoms included a change in the characteristics of discharge (color, consistency, odor), genital itching, and burning pain. Additionally, mixed vaginitis may be hard to eradicate, and recurrence is frequent. For example, fenticonazole was evaluated in a study, the eradication rate of mixed vaginitis was lower, and the relapse rate was higher than that of single vaginitis (Fabio Tumietto, 2019). This is likely due to the diverse behavior of the pathogenic vaginal flora that seems to affect the immune response of the host, making cure difficult.

\section{DIAGNOSIS OF MIXED VAGINITIS}

A mixed vaginitis diagnosis is made according to the presence of symptoms, clinical findings and laboratory tests (Gram-staining, wet-mount smears, PCR tests and combination of point-of-care tests) (Tempera et al., 2004). Some studies confirm that the presence of multiple vaginitis did not interfere with the assay performance (Vieira-Baptista et al., 2021). The key points in diagnosing mixed vaginitis are as follows (Sobel et al., 2013): an abnormal vaginal milieu and the simultaneous presence of at
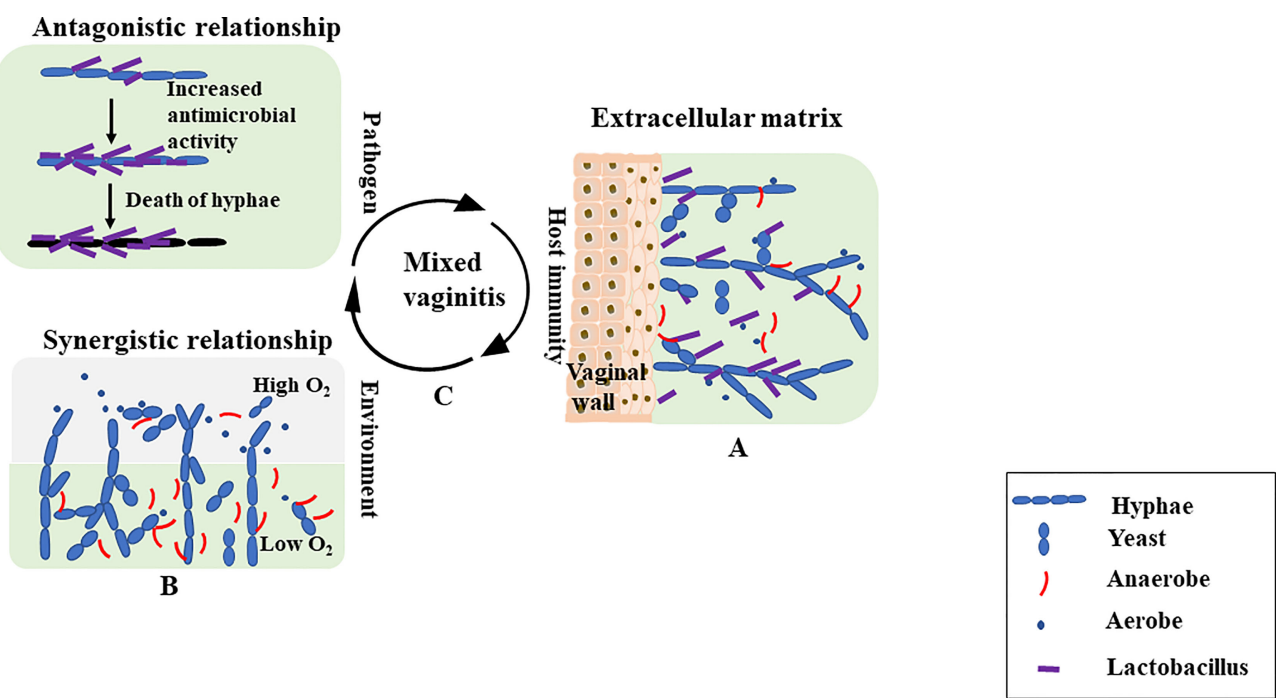

FIGURE 1 | (A) The mixed-biofilms are complex structures in which bacteria and/or fungi adhere to the vaginal wall surfaces, and they are encased in an extracellular matrix. The extracellular matrix is a physical barrier to the outside environment. (B) Microbes within the biofilm also exhibit antagonistic and synergistic interactions. Lactobacilli can attach to the surface of Candida albicans hyphae. Production of antimicrobials leads to the death of fungal filaments. In addition to antagonistic interactions, mutually beneficial interactions in mixed biofilm environments are also possible. For example, C. albicans can protect anaerobic bacteria by providing a low oxygen niche within the depths of the biofilm, even though the external environment is aerobic. (C) Antagonistic interactions are more likely to occur between probiotics and pathogens. Synergistic interactions are more likely to occur between pathogens. Different microbes can determine the course of mixed vaginitis. In interspecies interactions, many environmental cues (hypoxia, extracellular $\mathrm{pH}$, body temperature and $\mathrm{CO}_{2}$ ) and host immune factors could impact the formation of mixed vaginitis. 
TABLE 2 | A comparing the clinical manifestations and opportunistic pathogens in vaginitis.

\begin{tabular}{|c|c|c|c|c|}
\hline & & microbe & Pathogenic factor & Clinical manifestations \\
\hline AV/ & Endogenous & Streptococcus spp., S. aureus, Group & Host immune status & Approximately $10-20 \%$ asymptomatic. \\
\hline DIV & infection & B streptococci, E. coli and E. faecalis & $\begin{array}{l}\text { More sex partners } \\
\text { Hygiene practices } \\
\text { Intrauterine device } \\
\text { (IUD) } \\
\text { Antibiotic therapy }\end{array}$ & $\begin{array}{l}\text { Symptoms: inflammation, introital and vaginal redness, stinging and burning } \\
\text { sensations, the presence of sticky, yellow vaginal discharge and } \\
\text { dyspareunia. } \\
\text { Signs: vaginal discharge is described as homogeneous and purulent, } \\
\text { yellowish or yellow-green in color. }\end{array}$ \\
\hline BV & & $\begin{array}{l}\text { G. vaginalis, Prevotella spp., } \\
\text { A. vaginae, Megasphaera type 1, and } \\
\text { numerous other fastidious } \\
\text { or uncultivated anaerobes }\end{array}$ & Immunosuppression & $\begin{array}{l}\text { Approx. } 50 \% \text { asymptomatic. } \\
\text { Symptoms: a fishy odor of vaginal discharge. } \\
\text { Signs: homogeneous, thin discharge (milk-like consistency) that smoothly } \\
\text { coats the vaginal walls. }\end{array}$ \\
\hline WC & & $\begin{array}{l}\text { Candida albicans } \\
\text { Non-albicans Candidiasis }\end{array}$ & & $\begin{array}{l}\text { Approx. } 60 \% \text { women colonized. Minority develop symptoms. } \\
\text { Symptoms: external dysuria and vulvar pruritus, pain, swelling, and redness. } \\
\text { Signs: vulvar edema, fissures, excoriations, and thick curdy vaginal } \\
\text { discharge. }\end{array}$ \\
\hline CV & & Lactobacillus spp. & Estrogen & Symptoms and Signs are overlap with WC. \\
\hline TV & Exogenous infection & Trichomonas vaginalis & $\begin{array}{l}\text { Sexual transmission } \\
\text { Public baths and } \\
\text { articles }\end{array}$ & $\begin{array}{l}\text { Approx.10-50\% asymptomatic and } 5-15 \% \text { no abnormal signs. } \\
\text { Symptoms: vaginal discharge which can be diffuse, malodorous, or yellow- } \\
\text { green with or without vulvar irritation. } \\
\text { Signs: inflammation, introital and vaginal redness, stinging and burning } \\
\text { sensations and a strawberry-appearing cervix. }\end{array}$ \\
\hline MV & $\begin{array}{l}\text { Endogenous add/or } \\
\text { exogenous infection }\end{array}$ & $\begin{array}{l}\text { Simultaneous presence of at least two } \\
\text { vaginal pathogens }\end{array}$ & $\begin{array}{l}\text { Host immune status } \\
\text { Polymicrobial } \\
\text { interactions }\end{array}$ & $\begin{array}{l}\text { Symptoms and signs can be characterized by single vaginitis, can also } \\
\text { simultaneous presence of two or more potential vaginitis features. }\end{array}$ \\
\hline
\end{tabular}

AV, aerobic vaginitis; $D I V$, severe $A V$ is desquamative inflammatory vaginitis; $B V$, bacterial vaginosis; $W C$, vulvovaginal candidiasis; $C V$, cytolytic vaginosis; $T V$, trichomoniasis; $M V$, mixed vaginitis

least two types of vaginitis. Since the diagnosis of mixed vaginitis is largely dependent on the diagnostic criteria for single vaginitis, the criteria to facilitate recognition of the coexistence of multiple pathogens are as follows. Microphotographs of Gram-staining smear with mixed vaginitis are shown in Figure 2.

DIV/AV: The diagnosis of DIV/AV should be based on a combination of clinical features and microscopic findings (Oerlemans et al., 2020). The clinical features are as follows: vulvar erythema; vulvar swelling; thinning of the vaginal mucosa; vaginal congestion; scattered bleeding points; and yellow-colored vaginal secretion, increased discharge or pruritus. The microscopic features were as follows: wet mount smears with an DIV/AV score $\geq 3$ (Tempera et al., 2004). Accordingly, three main characteristics according to the guidelines from "Vaginitis and Microbiome Committee" of the International Society (Vieira-Baptista et al., 2021): ratio leukocytes: epithelial cells of greater than 1; presence of parabasal cells; and a disturbed bacterial community lacking the commonly observed high abundance of lactobacilli. Culture is not recommended for diagnosis, and a positive vaginal culture does not indicate the woman has DIV/AV. However, culture may be useful for treatment (Sherrard et al., 2018). In addition, some groups have begun to develop a nucleic acid amplification test (NAAT) to circumvent microscopic defects. However, the detailed information obtained with phase contrast microscopy is irreplaceable because it is still unclear whether DIV/AV is an "infection" or "dysbiosis".

BV: at least one of the following must be present: a Nugent score (Nugent et al., 1991) >6; the Nugent score is considered the gold standard for studies and relies upon estimating the relative proportions of bacterial morphotypes on a gram-stained vaginal smear to assign a score between 0 and 10. The presence of three of four Amsel's criteria, including homogeneous, thin, white discharge that smoothly coats the vaginal wall; clue-cells on microscopic examination (prerequisite); $\mathrm{pH}$ of vaginal fluid $>4.5$; or vaginal discharge with a fishy odor before or after the addition of $10 \% \mathrm{KOH}$ (whiff test). Amsel's criteria have a sensitivity of $37-$ $70 \%$ compared to the Nugent score, and has a poor performance for the diagnosis of BV (Vieira-Baptista et al., 2021). Moreover, multiple point-of-care (POC) tests are available for BV diagnosis. The Osom BV Blue test (Sekisui Diagnostics, Framingham, MA, USA) detects vaginal sialidase activity. This test has been reported to be most useful for symptomatic women in conjunction with vaginal $\mathrm{pH}$ and amine odor. In addition to the POC test, multiple BV NAATs are available among symptomatic women. Commercial tests (BD Max Vaginal Panel, Aptima BV and Seegene Allplex, etc.) are performed very well. NAATs will be the future for the diagnosis of BV but traditional methods of BV diagnosis, including the POC tests and Nugent score, remain useful because of their lower cost and rapid diagnosis (Workowski et al., 2021).

VVC: at least one of the following must be present: the presence of yeast or pseudohyphae in vaginal discharge on wet-mount microscopy with either saline or $10-20 \% \mathrm{KOH}$ solution (40-60\% sensitivity); the presence of yeasts or pseudohyphae on gram staining (up to $65 \%$ sensitivity) of vaginal discharge; or positivity on culture, which is helpful in diagnosing recurrent or complicated vulvovaginal candidiasis because species other than C. albicans (e.g., Candida glabrata, Candida tropicalis) may be present (Sherrard et al., 2018).

$\mathrm{CV}$ : The diagnosis of CV should be based on a combination of clinical features and microscopic findings. The signs and symptoms of CV are as follows (Hacisalihoğlu and Acet, 2021): vulvar and vaginal itching and burning, entry dyspareunia and a 

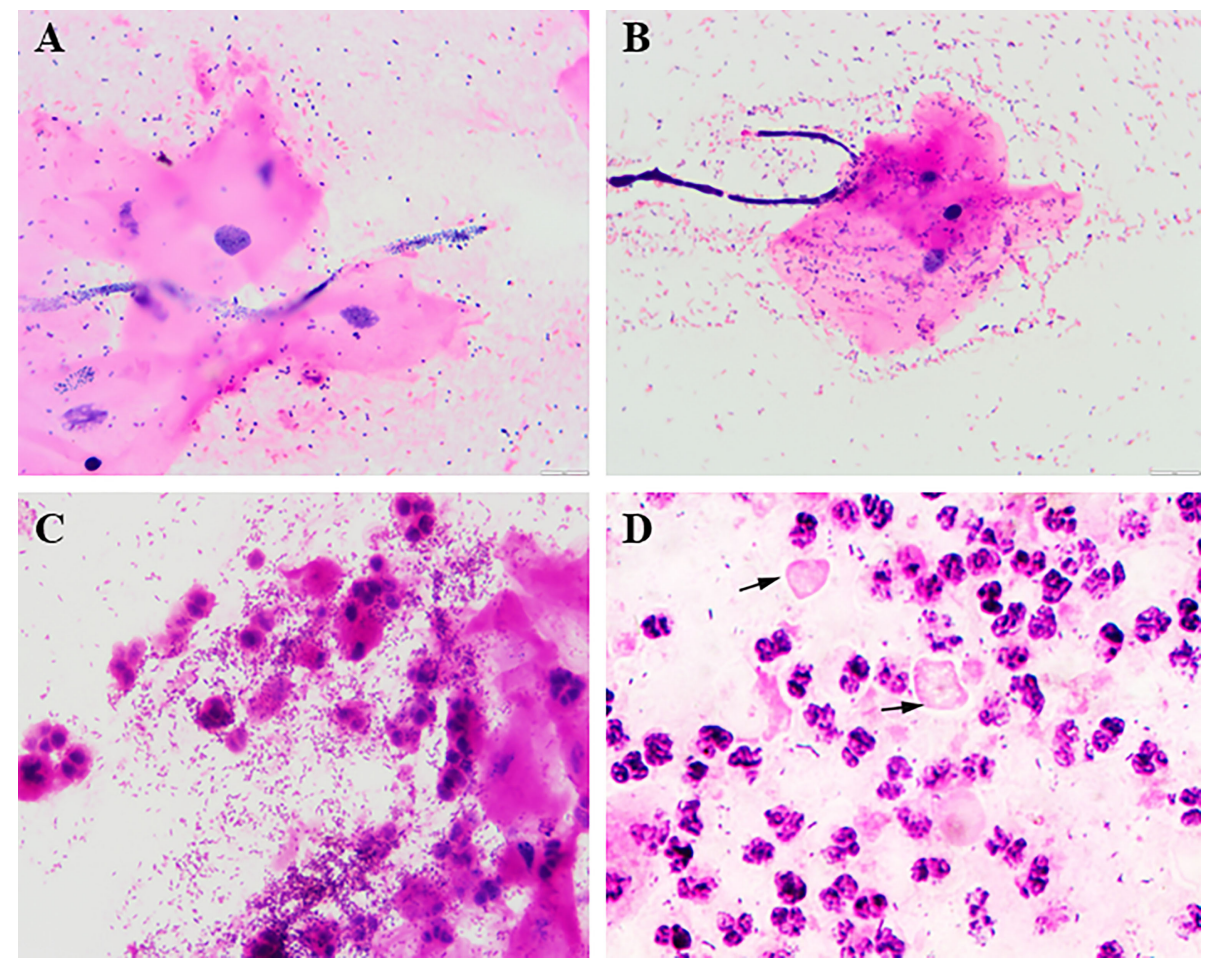

FIGURE 2 | Mixed vaginitis under Gram staining smears (1000x). (A) Candida + coccus; (B) Candida + BV; (C) BV + inflammation; (D) TV + DIV/AV; arrows indicate Trichomonas.

scant amount of white, frothy or cheesy vaginal discharge. The laboratory diagnosis follows a Cibley's criteria: absence of Trichomonas, Gardnerella or Candida; an increased number of lactobacilli (often adherent to the intermediate epithelial cell); a paucity of white cells; evidence of cytolysis with bare or naked intermediate nuclei; and a pH between 3.5 to 4.5 (Cibley and Cibley, 1991).

TV: at least one of the following must be present: positivity on wet-mount smear, although the sensitivity has been reported to be as low as 45-60\% (Nye et al., 2009); positivity on culture, which has a higher sensitivity than microscopy but is not widely available in clinical settings; or positivity on NAAT, which has the highest sensitivity for the detection of TV in comparison to both microscopy and culture. The Guidelines Group recommends that the most effective tests to diagnose TV in women are NAATs (Sherrard et al., 2018). However, examination of wet-mount preparations is still commonly used in clinical practice.

\section{LIMITATIONS OF MIXED VAGINITIS DIAGNOSIS}

Although clinical laboratory testing and clinical findings can identify the mixed vaginitis cause in the majority of women, inaccurate diagnosis or failure to recognize mixed vaginitis may occur in the following situations. Given the overlap between the signs and symptoms in various vaginitis, it is difficult to draw firm conclusions. For example, a yellow or green-yellow discharge was usually observed in patients with a single DIV/ AV. However, patients with DIV/AV mixed vaginitis (e.g., DIV/ AV plus BV, DIV/AV plus VVC) usually also report a greenyellow, thin, purulent vaginal discharge. Another reason for misdiagnosis is coinfection with cervical pathogens. Cervicitis frequently is asymptomatic; however, certain women might report an abnormal vaginal discharge. When a patient has inflammation along with BV, we must suspect that cervicitis/ PID or TV is also present, and women with TV sometimes might have a strawberry-appearing cervix. Therefore, amalgamative infection of the cervical and vagina should be recognized. Some cervical infections caused by pathogens, such as HSV-2, CT, NG, and mycoplasma (Curry et al., 2019), might occur concurrently with vaginitis, and symptoms of cervicitis are generally obscured, increasing the complexity of diagnosis. Thus, coinfection with the pathogens mentioned above should be excluded in the diagnosis of mixed vaginitis. Diagnostic testing for cervical infections should be performed for persons with mucous purulent discharge.

\section{TREATMENT}

Mixed vaginitis poses a therapeutic challenge. Consideration for polytherapy is appropriate for consecutive symptoms and signs in 
mixed vaginitis (e.g., symptomatic BV in patients following treatment of VVC; symptomatic VVC follows treatment of TV). However, polytherapy is unnecessary, particularly involving asymptomatic colonized microbes. Therefore, many countries have banned the availability of combination antimicrobial products for use in vaginitis. Standard treatment for mixed vaginitis has not yet been established. Although current in-clinic methods for the treatment of mixed vaginitis present wide variation, the treatment principles state the following: 1) according to microorganisms and pathogenesis, (e.g., treatment of DIV/AV adapted to the presence of three different components: infection, inflammation or atrophy) standard treatments should be chosen to minimize the abuse of unnecessary antibacterial drugs (Donders et al., 2017); 2) we should treat sexually transmitted infection first when the simultaneous presence of sexually transmitted disease (such as TV), meanwhile treating their sexual partners (Workowski and Bolan, 2015); and 3) we should treat single vaginitis with severe symptoms first when there is a contradiction in medication (Han et al., 2015) (such as treatment of DIV/AV plus VVC, if started by treating VVC, usually the symptoms disappear, and the vaginal flora changes to a more "normal" state). 4) Lay emphasis on alleviating patients' symptoms as soon as possible. One challenge is that individual signs and symptoms have shown only modest value in diagnosing mixed vaginitis. Therefore, how to identify at-polytherapy subpopulations requires further consideration.

Although anti-infective treatments are available and are usually highly efficient in eradicating microorganisms, the long-term efficiency is hampered by relapse (Cohen et al., 2020). How to reduce the recurrence of mixed vaginitis needs further exploration and confirmation in larger trials. The main treatment objectives are the alleviation of symptoms, the elimination of pathogens, and eventually the recovery from disturbed to healthy lactobacilli-dominated vaginal flora.

This review summarized the representative epidemiological data of mixed vaginitis and suggested that mixed vaginitis is a common cause of vulvovaginal symptoms. In contrast to research on single vaginitis, research on mixed vaginitis is still in the preliminary stage. Mixed vaginitis remains understudied and underrecognized. The pathogenic mechanism of mixed vaginitis needs to be further explored. Mixed vaginitis generally involves the formation of mixed biofilms. The study of polymicrobial interactions and mixed biofilms will provide a new idea for the understanding of mixed vaginitis. The nature of interspecies interactions can determine the fate of microbial populations. Thus, it appears possible to utilize these interactions for prophylactic and therapeutic within the host. Moreover, effective management of mixed vaginitis depends on laboratory diagnosis to avoid inappropriate therapy, recurrence, and reinfection. Although two types of vaginitis may be identified, a potential vaginitis may be present but may not be the cause of existing vaginal symptoms. Therefore, the accuracy of diagnosis and how to identify at-polytherapy subpopulations requires further consideration. In summary, this review is of great importance for improving clinical awareness of mixed vaginitis and facilitating female reproductive health.

\section{AUTHOR CONTRIBUTIONS}

The author is grateful to Xue $\mathrm{F}$ and Han $\mathrm{C}$, who provided suggestions for this review. Li $\mathrm{H}$, Wang $\mathrm{C}$, and Fan A made substantial contributions to drafting the article and revising it critically. Furthermore, all authors have given their final approval for this version to be published and agree to be accountable for all aspects of the work.

\section{FUNDING}

This work was supported by National Natural Science Foundation of China (No. 82101705), Tianjin Health Science and Technology Project (Grant number QN20034, KJ20176 and KJ20003) and Scientific Research Project of Tianjin Education Commission (Grant number 2020KJ158).

\section{REFERENCES}

Abdul-Aziz, M., Mahdy, M. A. K., Abdul-Ghani, R., Alhilali, N. A., Al-Mujahed, L. K. A., Alabsi, S. A., et al. (2019). Bacterial Vaginosis, Vulvovaginal Candidiasis and Trichomonal Vaginitis Among Reproductive-Aged Women Seeking Primary Healthcare in Sana'a City, Yemen. BMC Infect. Dis. 19 (1), 879. doi: 10.1186/s12879-019-4549-3

Beaussart, A., Herman, P., El-Kirat-Chatel, S., Lipke, P. N., Kucharikova, S., Van Dijck, P., et al. (2013). Single-Cell Force Spectroscopy of the Medically Important Staphylococcus Epidermidis-Candida Albicans Interaction. Nanoscale 5 (22), 10894-10900. doi: 10.1039/c3nr03272h

Bohbot, J. M., Sednaoui, P., Verriere, F., and Achhammer, I. (2012). [The Etiologic Diversity of Vaginitis]. Gynecol Obstet Fertil 40 (10), 578-581. doi: 10.1016/ j.gyobfe.2011.08.001

Brotman, R. M., Klebanoff, M. A., Nansel, T. R., Yu, K. F., Andrews, W. W., Zhang, J., et al. (2010). Bacterial Vaginosis Assessed by Gram Stain and Diminished Colonization Resistance to Incident Gonococcal, Chlamydial, and Trichomonal Genital Infection. J. Infect. Dis. 202 (12), 1907-1915. doi: $10.1086 / 657320$

Byun, S. W., Park, Y. J., and Hur, S. Y. (2016). Affirm VPIII Microbial Identification Test can be Used to Detect Gardnerella Vaginalis, Candida Albicans and Trichomonas Vaginalis Microbial Infections in Korean Women. J. obstetrics gynaecol Res. 42 (4), 422-426. doi: 10.1111/jog.12913

Carrillo-Avila, J. A., Serrano-Garcia, M. L., Fernandez-Parra, J., Sorlozano-Puerto, A., Navarro-Mari, J. M., Stensvold, C. R., et al. (2017). Prevalence and Genetic Diversity of Trichomonas Vaginalis in the General Population of Granada and Co-Infections With Gardnerella Vaginalis and Candida Species. J. Med. Microbiol. 66 (10), 1436-1442. doi: 10.1099/jmm.0.000603

Castro, J., Machado, D., and Cerca, N. (2016). Escherichia Coli and Enterococcus Faecalis are Able to Incorporate and Enhance a Pre-Formed Gardnerella Vaginalis Biofilm. Pathog. Dis. 74 (3), ftw007. doi: 10.1093/femspd/ftw007

Cibley, L. J., and Cibley, L. J. (1991). Cytolytic Vaginosis. Am. J. obstetrics gynecol 165 (4 Pt 2), 1245-1249. doi: 10.1016/S0002-9378(12)90736-X

Cohen, C. R., Wierzbicki, M. R., French, A. L., Morris, S., Newmann, S., Reno, H., et al. (2020). Randomized Trial of Lactin-V to Prevent Recurrence of Bacterial Vaginosis. N Engl. J. Med. 382 (20), 1906-1915. doi: 10.1056/NEJMoa1915254 Cools, P., Jespers, V., Hardy, L., Crucitti, T., Delany-Moretlwe, S., Mwaura, M., et al. (2016). A Multi-Country Cross-Sectional Study of Vaginal Carriage of 
Group B Streptococci (GBS) and Escherichia Coli in Resource-Poor Settings: Prevalences and Risk Factors. PloS One 11 (1), e0148052. doi: 10.1371/ journal.pone. 0148052

Curry, A., Williams, T., and Penny, M. L. (2019). Pelvic Inflammatory Disease: Diagnosis, Management, and Prevention. Am. Family physician 100 (6), 357-364.

Deidda, F., Amoruso, A., Allesina, S., Pane, M., Graziano, T., Del Piano, M., et al. (2016). In Vitro Activity of Lactobacillus Fermentum LF5 Against Different Candida Species and Gardnerella Vaginalis: A New Perspective to Approach Mixed Vaginal Infections? J. Clin. Gastroenterol. 50 Suppl 2), :S168-:SS70. doi: 10.1097/MCG.0000000000000692

Donders, G. G. G., Bellen, G., Grinceviciene, S., Ruban, K., and Vieira-Baptista, P. (2017). Aerobic Vaginitis: No Longer a Stranger. Res. Microbiol. 168 (9-10), 845-858. doi: 10.1016/j.resmic.2017.04.004

Donders, G. G., Grinceviciene, S., Ruban, K., and Bellen, G. (2020). Vaginal pH and Microbiota During Fluconazole Maintenance Treatment for Recurrent Vulvovaginal Candidosis (RVVC). Diagn. Microbiol. Infect. Dis. 97 (2), 115024. doi: 10.1016/j.diagmicrobio.2020.115024

Elkins, J. M., Cantillo-Campos, S., and Sheele, J. M. (2020). Frequency of Coinfection on the Vaginal Wet Preparation in the Emergency Department. Cureus 12 (11), el1566. doi: 10.7759/cureus.11566

Fabio Tumietto, B. P. M. S. (2019). Looking for Appropriateness in the Cure of Mixed Vaginitis: The Role of Fenticonazole as an Empiric Treatment. Future Microbiol. 14, 1349-1355. doi: 10.2217/fmb-2019-0189

Fan, A., Yue, Y., Geng, N., Zhang, H., Wang, Y., and Xue, F. (2013). Aerobic Vaginitis and Mixed Infections: Comparison of Clinical and Laboratory Findings. Arch. gynecol obstetrics 287 (2), 329-335. doi: 10.1007/s00404-012-2571-4

Fox, E. P., Cowley, E. S., Nobile, C. J., Hartooni, N., Newman, D. K., and Johnson, A. D. (2014). Anaerobic Bacteria Grow Within Candida Albicans Biofilms and Induce Biofilm Formation in Suspension Cultures. Curr. Biol. 24 (20), 24112416. doi: 10.1016/j.cub.2014.08.057

Gaydos, C. A., Beqaj, S., Schwebke, J. R., Lebed, J., Smith, B., Davis, T. E., et al. (2017). Clinical Validation of a Test for the Diagnosis of Vaginitis. Obstetrics gynecol 130 (1), 181-189. doi: 10.1097/AOG.0000000000002090

Gondo, F., da Silva, M. G., Polettini, J., Tristao Ada, R., Peracoli, J. C., Witkin, S. S., et al. (2011). Vaginal Flora Alterations and Clinical Symptoms in Low-Risk Pregnant Women. Gynecol Obstet Invest. 71 (3), 158-162. doi: 10.1159/ 000316051

Hacısalihoğlu, U. P., and Acet, F. (2021). A Clinicopathological Diagnostic and Therapeutic Approach to Cytolytic Vaginosis: An Extremely Rare Entity That may Mimic Vulvovaginal Candidiasis. J. cytol 38 (2), 88-93. doi: 10.4103/ JOC.JOC_169_20

Han, C., Wu, W., Fan, A., Wang, Y., Zhang, H., Chu, Z., et al. (2015). Diagnostic and Therapeutic Advancements for Aerobic Vaginitis. Arch. gynecol obstetrics 291 (2), 251-257. doi: 10.1007/s00404-014-3525-9

Harriott, M. M., and Noverr, M. C. (2010). Ability of Candida Albicans Mutants to Induce Staphylococcus Aureus Vancomycin Resistance During Polymicrobial Biofilm Formation. Antimicrob. Agents Chemother. 54 (9), 3746-3755. doi: 10.1128/AAC.00573-10

Hillier, S. L., Austin, M., Macio, I., Meyn, L. A., Badway, D., and Beigi, R. (2021). Diagnosis and Treatment of Vaginal Discharge Syndromes in Community Practice Settings. Clin. Infect. Dis. an Off. Publ. Infect. Dis. Soc. America 72 (9), 1538-1543. doi: 10.1093/cid/ciaa260

Jahic, M., Mulavdic, M., Nurkic, J., Jahic, E., and Nurkic, M. (2013). Clinical Characteristics of Aerobic Vaginitis and its Association to Vaginal Candidiasis, Trichomonas Vaginitis and Bacterial Vaginosis. Med. Arch. 67 (6), 428-430. doi: 10.5455/medarh.2013.67.428-430

Kamga, Y. M., Ngunde, J. P., and Akoachere, J. K. T. (2019). Prevalence of Bacterial Vaginosis and Associated Risk Factors in Pregnant Women Receiving Antenatal Care at the Kumba Health District (KHD), Cameroon. BMC Pregnancy Childbirth 19 (1), 166. doi: 10.1186/s12884-019-2312-9

Khan, Z., Bhargava, A., Mittal, P., Bharti, R., Puri, P., Khunger, N., et al. (2019). Evaluation of Reliability of Self-Collected Vaginal Swabs Over PhysicianCollected Samples for Diagnosis of Bacterial Vaginosis, Candidiasis and Trichomoniasis, in a Resource-Limited Setting: A Cross-Sectional Study in India. BMJ Open 9 (8), e025013. doi: 10.1136/bmjopen-2018-025013

Konadu, D. G., Owusu-Ofori, A., Yidana, Z., Boadu, F., Iddrisu, L. F., Adu-Gyasi, D., et al. (2019). Prevalence of Vulvovaginal Candidiasis, Bacterial Vaginosis and Trichomoniasis in Pregnant Women Attending Antenatal Clinic in the Middle Belt of Ghana. BMC Pregnancy Childbirth 19 (1), 341. doi: 10.1186/ s12884-019-2488-Z

Laniewski, P., Ilhan, Z. E., and Herbst-Kralovetz, M. M. (2020). The Microbiome and Gynaecological Cancer Development, Prevention and Therapy. Nat. Rev. Urol 17 (4), 232-250. doi: 10.1038/s41585-020-0286-Z

Liang, Q., Li, N., Song, S., Zhang, A., Li, N., and Duan, Y. (2016). High-Dose Nifuratel for Simple and Mixed Aerobic Vaginitis: A Single-Center Prospective Open-Label Cohort Study. J. obstetrics gynaecol Res. 42 (10), 1354-1360. doi: 10.1111/jog. 13052

Lohse, M. B., Gulati, M., Johnson, A. D., and Nobile, C. J. (2018). Development and Regulation of Single- and Multi-Species Candida Albicans Biofilms. Nat. Rev. Microbiol. 16 (1), 19-31. doi: 10.1038/nrmicro.2017.107

Mardha KT, P. A., Elshibly a, S., and Hellbergb, D. (1998). Symptoms And Signs in Single and Mixed Genital Infections. Int. J. Gynecol Obstetrics 63, 145-152. doi: 10.1016/S0020-7292(98)00140-4

Morales, D. K., Grahl, N., Okegbe, C., Dietrich, L. E., Jacobs, N. J., and Hogan, D. A. (2013). Control of Candida Albicans Metabolism and Biofilm Formation by Pseudomonas Aeruginosa Phenazines. mBio 4 (1), e00526-e00512. doi: 10.1128/mBio.00526-12

Nugent, R. P., Krohn, M. A., and Hillier, S. L. (1991). Reliability of Diagnosing Bacterial Vaginosis is Improved by a Standardized Method of Gram Stain Interpretation. J. Clin. Microbiol. 29 (2), 297-301. doi: 10.1128/jcm.29.2. 297-301.1991

Nye, M. B., Schwebke, J. R., and Body, B. A. (2009). Comparison of APTIMA Trichomonas Vaginalis Transcription-Mediated Amplification to Wet Mount Microscopy, Culture, and Polymerase Chain Reaction for Diagnosis of Trichomoniasis in Men and Women. Am. J. obstetrics gynecol 200 (2), 188.e1-188.e7. doi: 10.1016/j.ajog.2008.10.005

Nyirjesy, P., Banker, W. M., and Bonus, T. M. (2020). Physician Awareness and Adherence to Clinical Practice Guidelines in the Diagnosis of Vaginitis Patients: A Retrospective Chart Review. Popul Health Manage. 23 (S1), S13s21. doi: $10.1089 /$ pop. 2020.0258

Oerlemans, E. F. M., Wuyts, S., Bellen, G., Wittouck, S., De Boeck, I., Ruban, K., et al. (2020). The Dwindling Microbiota of Aerobic Vaginitis, an Inflammatory State Enriched in Pathobionts With Limited TLR Stimulation. Diagn (Basel Switzerland) 10 (11), 879. doi: 10.3390/diagnostics10110879

Pacha-Herrera, D., Vasco, G., Cruz-Betancourt, C., Galarza, J. M., Barragan, V., and Machado, A. (2020). Vaginal Microbiota Evaluation and Lactobacilli Quantification by qPCR in Pregnant and Non-Pregnant Women: A Pilot Study. Front. Cell Infect. Microbiol. 10, 303. doi: 10.3389/fcimb.2020.00303

Peters, B. M., and Noverr, M. C. (2013). Candida Albicans-Staphylococcus Aureus Polymicrobial Peritonitis Modulates Host Innate Immunity. Infect. Immun. 81 (6), 2178-2189. doi: 10.1128/IAI.00265-13

Rivers, C. A., Adaramola, O. O., and Schwebke, J. R. (2011). Prevalence of Bacterial Vaginosis and Vulvovaginal Candidiasis Mixed Infection in a Southeastern American STD Clinic. Sexually transmitted Dis. 38 (7), 672-674. doi: 10.1097/ OLQ.0b013e31820fc3b8

Roux, D., Gaudry, S., Dreyfuss, D., El-Benna, J., de Prost, N., Denamur, E., et al. (2009). Candida Albicans Impairs Macrophage Function and Facilitates Pseudomonas Aeruginosa Pneumonia in Rat. Crit. Care Med. 37 (3), $1062-$ 1067. doi: 10.1097/CCM.0b013e31819629d2

Salinas, A. M., Osorio, V. G., Pacha-Herrera, D., Vivanco, J. S., Trueba, A. F., and Machado, A. (2020). Vaginal Microbiota Evaluation and Prevalence of Key Pathogens in Ecuadorian Women: An Epidemiologic Analysis. Sci. Rep. 10 (1), 18358. doi: 10.1038/s41598-020-74655-Z

Saunders, S., Bocking, A., Challis, J., and Reid, G. (2007). Effect of Lactobacillus Challenge on Gardnerella Vaginalis Biofilms. Colloids surfaces B Biointerfaces 55 (2), 138-142. doi: 10.1016/j.colsurfb.2006.11.040

Schlecht, L. M., Peters, B. M., Krom, B. P., Freiberg, J. A., Hansch, G. M., Filler, S. G., et al. (2015). Systemic Staphylococcus Aureus Infection Mediated by Candida Albicans Hyphal Invasion of Mucosal Tissue. Microbiol. (Reading) 161 (Pt 1), 168-181. doi: 10.1099/mic.0.083485-0

Schwebke, J. R., Taylor, S. N., Ackerman, R., Schlaberg, R., Quigley, N. B., Gaydos, C. A., et al. (2020). Clinical Validation of the Aptima Bacterial Vaginosis and Aptima Candida/Trichomonas Vaginitis Assays: Results From a Prospective Multicenter Clinical Study. J. Clin. Microbiol. 58 (2), e01643-19. doi: 10.1128/ JCM.01643-19 
Sherrard, J. (2019). Evaluation of the BD MAX Vaginal Panel for the Detection of Vaginal Infections in a Sexual Health Service in the UK. Int. J. STD AIDS 30 (4), 411-414. doi: 10.1177/0956462418815284

Sherrard, J., Wilson, J., Donders, G., Mendling, W., and Jensen, J. S. (2018). European (IUSTI/WHO) International Union Against Sexually Transmitted Infections (IUSTI) World Health Organisation (WHO) Guideline on the Management of Vaginal Discharge. Int. J. STD AIDS 29 (13), 1258-1272. doi: 10.1177/0956462418785451

Sobel, J. D., Subramanian, C., Foxman, B., Fairfax, M., and Gygax, S. E. (2013). Mixed Vaginitis-More Than Coinfection and With Therapeutic Implications. Curr. Infect. Dis. Rep. 15 (2), 104-108. doi: 10.1007/s11908013-0325-5

Tempera, G., Bonfiglio, G., Cammarata, E., Corsello, S., and Cianci, A. (2004). Microbiological/clinical Characteristics and Validation of Topical Therapy With Kanamycin in Aerobic Vaginitis: A Pilot Study. Int. J. antimicrob Agents 24 (1), 85-88. doi: 10.1016/j.ijantimicag.2003.12.013

Venugopal, S., Gopalan, K., Devi, A., and Kavitha, A. (2017). Epidemiology and Clinico-Investigative Study of Organisms Causing Vaginal Discharge. Indian J. Sex Transm Dis. AIDS 38 (1), 69-75. doi: 10.4103/0253-7184.203433

Vieira-Baptista, P., Grinceviciene, S., Oliveira, C., Fonseca-Moutinho, J., Cherey, F., and Stockdale, C. K. (2021). The International Society for the Study of Vulvovaginal Disease Vaginal Wet Mount Microscopy Guidelines: How to Perform, Applications, and Interpretation. J. Low Genit Tract Dis. 25 (2), 172 180. doi: 10.1097/LGT.0000000000000595

Vieira-Baptista, P., Silva, A. R., Costa, M., Aguiar, T., Saldanha, C., and Sousa, C. (2021). Clinical Validation of a New Molecular Test (Seegene Allplex Vaginitis) for the Diagnosis of Vaginitis: A Cross-Sectional Study. BJOG an Int. J. obstetrics gynaecol 128 (8), 1344-1352. doi: 10.1111/1471-0528.16661

Vieira-Baptista, P., Silva, A. R., Costa, M., Figueiredo, R., Saldanha, C., and Sousa, C. (2021). Diagnosis of Bacterial Vaginosis: Clinical or Microscopic? A CrossSectional Study. Int. J. gynaecol obstetrics: Off. Organ Int. Fed. Gynaecol Obstetrics. doi: 10.1097/LGT.0000000000000595

Wang, Z. L., Fu, L. Y., Xiong, Z. A., Qin, Q., Yu, T. H., Wu, Y. T., et al. (2016). Diagnosis and Microecological Characteristics of Aerobic Vaginitis in
Outpatients Based on Preformed Enzymes. Taiwan J. Obstet Gynecol 55 (1), 40-44. doi: 10.1016/j.tjog.2015.06.012

Wang, H., Huang, Z., Wu, Z., Qi, X., and Lin, D. (2017). An Epidemiological Study on Vaginitis in 6,150 Women of Reproductive Age in Shanghai. New Microbiol 40 (2), 113-118.

Workowski, K., Bachmann, L., Chan, P., Johnston, C., Muzny, C., Park, I., et al. (2021). Sexually Transmitted Infections Treatment Guidelines, 2021. MMWR Recomm. Rep. 70, 4, 1-187. doi: 10.15585/mmwr.rr7004a1

Workowski, K. A., and Bolan, G. A. (2015). Sexually Transmitted Diseases Treatment Guidelines, 2015. MMWR Recommendations and Reports : Morbidity and Mortality Weekly Report Recommendations and Reports. MMWR Recomm. Rep. 64, Rr-03, 1-137.

Yu, X. Y., Fu, F., Kong, W. N., Xuan, Q. K., Wen, D. H., Chen, X. Q., et al. (2018) Streptococcus Agalactiae Inhibits Candida Albicans Hyphal Development and Diminishes Host Vaginal Mucosal TH17 Response. Front. Microbiol. 9, 198. doi: $10.3389 /$ fmicb. 2018.00198

Conflict of Interest: The authors declare that the research was conducted in the absence of any commercial or financial relationships that could be construed as a potential conflict of interest.

Publisher's Note: All claims expressed in this article are solely those of the authors and do not necessarily represent those of their affiliated organizations, or those of the publisher, the editors and the reviewers. Any product that may be evaluated in this article, or claim that may be made by its manufacturer, is not guaranteed or endorsed by the publisher.

Copyright (C) 2021 Qi, Li, Wang, Li, Zhang, Dong, Fan, Han and Xue. This is an openaccess article distributed under the terms of the Creative Commons Attribution License (CC BY). The use, distribution or reproduction in other forums is permitted, provided the original author(s) and the copyright owner(s) are credited and that the original publication in this journal is cited, in accordance with accepted academic practice. No use, distribution or reproduction is permitted which does not comply with these terms. 